\title{
Coronary Atherosclerosis in Rheumatoid Arthritis: Could Endothelial Progenitor Cells Be the Missing Link?
}

Patients with rheumatoid arthritis (RA) have a reduced life expectancy of $5-10$ years ${ }^{1}$, largely driven by its association with an increased risk of cardiovascular disease (CVD), which accounts for about half of all deaths in patients with $\mathrm{RA}^{2}$. The reasons for such a disproportionately high risk compared to the general population are not yet fully understood, but conventional risk factors alone do not appear to fully account for the difference ${ }^{3}$. It follows that conventional CV risk stratification tools, such as the Framingham risk score, used so widely in primary prevention in the general population, may not be as well suited for use in patients with RA.

Arguably the most appropriate algorithm of $\mathrm{CV}$ risk assessment for this cohort of patients may be the Reynolds risk score, which includes the measurement of high sensitivity C-reactive protein (CRP), reflecting the underlying inflammatory nature to atherosclerosis ${ }^{4}$. Another tool to improve coronary risk stratification is coronary artery calcium (CAC) scoring by computed tomography, which has gained popularity in recent years. High CAC scores have been associated with an increase in all-cause mortality ${ }^{5}$, and patients with RA have a higher prevalence and a greater burden of coronary calcification than non-RA controls. Therefore, its application for measuring subclinical atherosclerosis in this patient cohort could be utilized. However, pathophysiological links between arterial calcium deposition and atherosclerotic plaque formation are not completely clear, and clinical utility of CAC as well as the Reynolds risk score as a risk stratification tool has not been well validated in RA patients; therefore, the challenge of trying to predict patients who are most at risk continues ${ }^{6}$.

The process of atherogenesis has been fundamentally linked to endothelial injury unbalanced by appropriate endothelial recovery, which appears to be at least partly attributable to the impairment of mobilization and function of endothelial progenitor cells (EPC) ${ }^{7-9}$ It has been suggested that the number of circulating EPC may serve as a marker of CV risk ${ }^{10}$. Indeed, reduced levels of EPC have been shown to be associated with increased incidence of coronary artery disease, $\mathrm{CV}$ events, and death from $\mathrm{CV}$ causes, independent of conventional risk factors ${ }^{11,12}$. Moreover, levels of EPC have been shown to be a better predictor of endothe- lial dysfunction (measured by flow-mediated brachial reactivity) than the Framingham risk score ${ }^{13}$. However, in contrast, some have reported an increase in the number of EPC in stable patients, proportional to the severity of coronary disease on coronary angiography ${ }^{14}$. Therefore, whether EPC correlate positively or negatively with CVD is seemingly more complex. Some of this inconsistency may be due to the current controversy surrounding the definition of EPC and the possibility that investigators use different methodological techniques to identify them.

There are two fundamental techniques to study EPC. First, flow cytometry has been used to quantify EPC based on cell surface markers, including CD34 (found in both immature endothelial cells and hematopoietic stem cells), KDR (kinase insert domain receptor on endothelial cells for vascular endothelial growth factor, VEGF), and CD133 (expressed on hemopoietic stem cells). Unfortunately, the theory that these markers identify EPC is open to criticism, not least because these antigens are also expressed on subpopulations of hematopoietic progenitor cells and also because it presumes that these cells will differentiate into functional endothelium. A second technique, cell culture, is useful for evaluating functionality of these putative EPC compared with differentiated endothelial cells. Using a human endothelial cell-specific angiogenesis assay, 2 functionally distinct populations of cells have been grown from mononuclear cells, classified according to the time at which they appeared in culture ${ }^{15}$.

The first to appear, so called "early" EPC, express CD14 (monocyte marker) and CD45 (common leukocyte marker) and do not form new vessels de novo but seem to facilitate angiogenesis in a paracrine fashion by the release of chemokines. For this reason, some have renamed them circulating angiogenic cells. They typically appear as early as at 3 days in culture, have limited proliferative potential, and disappear after 2 weeks. These early cells have been identified in many previous studies by the use of the colony forming unit-endothelial cell assay and some would argue that this technique should no longer be used to study EPC. The second group, late outgrowth endothelial cells (OEC), have powerful long-lasting proliferative capacity resulting in formation of functional mature endothelium and neovessel for-

See Role of circulating EPC in RA patients with coronary calcification, page 529

Personal non-commercial use only. The Journal of Rheumatology Copyright @ 2010 . All rights reserved. 
mation, hence representing "true" EPC. Such OEC colonies grow from a very rare subset of CD34+ CD14-negative CD45-negative cells and express KDR. Importantly, highly purified CD133+ cells have been unable to generate OEC in culture $^{16}$. In the current absence of an identifiable specific surface marker for EPC, cells defined solely by the presence of CD34, KDR, and CD133, without comment on functionality, might be regarded as stem cells that are involved in the angiogenesis pathway, but may not necessarily go on to form the endothelium itself.

RA is a systemic inflammatory condition and associates with high levels of pro-angiogenic markers, such as VEGF $^{17}$. Thus, it could be hypothesized that levels of EPC would be higher among patients with RA. Interestingly, Grisar, et al observed that CD34+KDR+CD133+ cells were significantly decreased in patients with active RA compared to those with low disease activity, and healthy controls ${ }^{18}$. In those with active disease, disease modifying antirheumatic drugs had no impact on EPC levels, but patients receiving anti-tumor necrosis factor (TNF) therapy had comparable numbers to those with low disease activity and healthy controls. Regardless of whether or not these triple positive cells truly represent EPC, the negative correlation may be important given their proven association with unfavorable $\mathrm{CV}$ prognosis.

In this issue of The Journal, Yiu, et al ${ }^{19}$ attempt to close the triangle of association between RA, subgroups of EPC, and coronary atherosclerosis. Their study compared 70 patients with RA (without established CVD) to 35 age and sex matched healthy controls. All subjects underwent CAC score measurement and flow cytometry to identify EPC subpopulations. Four subpopulations of EPC were defined: CD34+, CD34+/KDR+, CD133+, CD133+/KDR+. Just over one-fifth (21\%) of RA patients had coronary atherosclerosis (defined as calcium score $\geq 10$ Agatston units). There were no significant differences in EPC subgroups between RA patients and controls, possibly related to the low disease activity, measured by CRP. However, in those RA patients who had significant coronary atherosclerosis the numbers of CD133+ and CD133+/KDR+ cells were significantly lower than in those without coronary atherosclerosis $(\mathrm{p}<0.01)$. In addition, older age and lower CD133+/KDR+ were identified as independent predictors of coronary atherosclerosis.

However, the potential for using EPC as a surrogate marker for coronary artery disease highlighted by Yiu, et $a l^{19}$ may be hampered by some perplexity surrounding EPC. Much of this is driven by the disagreement as to what actually constitutes an EPC. Flow cytometry has the disadvantage of measuring only surface markers, which can be present on other cell lineages, while cell culture is complex and time-consuming. While Yiu, et al ${ }^{19}$ may claim that CD133+ cells are immature EPC, this could be challenged in the light of the evidence presented earlier, namely that they are more likely to be stem cells involved in angiogenesis by releasing angiogenic factors that provide the building material for the repopulation of dysfunctional endothelium.

Another potential limitation of their study is that not all atherosclerotic plaques are calcified. Indeed it has been suggested that RA patients have more vulnerable plaques despite less extensive atherosclerotic burden overall ${ }^{20}$. This is something that a CAC score would not identify, and further research is needed to establish the relation of the score with future $\mathrm{CV}$ events in patients with RA.

Regardless of the semantics surrounding EPC definition, Yiu, et $a l^{19}$ have suggested a potential link between the depletion of CD133/KDR+ cells and coronary atherosclerosis in patients with RA. There are - of course - more questions than answers. It is not clear whether reduced EPC contribute to the pathophysiology of atherosclerosis or are depressed by some overwhelming causative factor, which also contributes to the coronary artery disease itself. CD133+ cells were particularly depressed in RA patients with coronary atherosclerosis while CD34+ cells were unaffected. This contrasts with previous work in the general population showing CD34+/KDR+ EPC levels to be significantly negatively correlated with carotid intima-media thickness, another surrogate of atherosclerosis, in healthy subjects ${ }^{21}$. Perhaps CD133+ cells are in some way preferentially targeted in patients with RA and coronary atherosclerosis. If so, the mechanism at this stage is far from clear. Biological agents such as anti-TNF therapy appear to increase EPC levels in RA, but the impact on coronary atherosclerosis is unclear and needs to be addressed. What is clear is that RA is associated with increased CVD, and risk stratification is often difficult because standard tools have not been validated for this patient cohort. The use of a biomarker, such as EPC, may be attractive and may help to identify RA patients at high risk for coronary artery disease, allowing for a more aggressive risk-reducing strategy. Equally exciting might be the promise of possibly manipulating EPC through stem cell treatment, perhaps reducing atherosclerotic burden in patients most at risk ${ }^{22}$. Further work in this area is clearly needed.

\section{BENJAMIN J. WRIGLEY, MRCP; GREGORY Y.H. LIP, MD; EDUARD SHANTSILA, MD,}

Haemostasis Thrombosis and Vascular Biology Unit, University of Birmingham Centre for Cardiovascular Sciences, City Hospital,

Birmingham B18 7QH, England, UK.

Address correspondence to Dr. Shantsila; E-mail: shantsila@yandex.ru

\section{REFERENCES}

1. Kvien TK. Epidemiology and burden of illness of rheumatoid arthritis. Pharmacoeconomics 2004;22 Suppl 1:1-12.

2. Pincus T, Callahan LF. Taking mortality in rheumatoid arthritis seriously - predictive markers, socioeconomic status and

Personal non-commercial use only. The Journal of Rheumatology Copyright @ 2010 . All rights reserved. 
comorbidity. J Rheumatol 1986;13:841-5.

3. Toms TE, Panoulas VF, Douglas KM, Griffiths H, Sattar N, Smith JP, et al. Statin use in rheumatoid arthritis in relation to actual cardiovascular risk: evidence for substantial under treatment of lipid associated cardiovascular risk? Ann Rheum Dis 2009 Oct 23. [Epub ahead of print]

4. Ridker PM, Buring JE, Rifai N, Cook NR. Development and validation of improved algorithms for the assessment of global cardiovascular risk in women: the Reynolds Risk Score. JAMA 2007;297:611-9.

5. Shaw LJ, Raggi P, Schisterman E, Berman DS, Callister TQ. Prognostic value of cardiac risk factors and coronary artery calcium screening for all-cause mortality. Radiology 2003;228:826-33.

6. Schurgers LJ, Cranenburg EC, Vermeer C. Matrix Gla-protein: the calcification inhibitor in need of vitamin K. Thromb Haemost 2008;100:593-603.

7. Hristov M, Zernecke A, Liehn EA, Weber C. Regulation of endothelial progenitor cell homing after arterial injury. Thromb Haemost 2007;98:274-7.

8. Shantsila E, Watson T, Lip GY. Endothelial progenitor cells in cardiovascular disorders. J Am Coll Cardiol 2007;49:741-52.

9. Shantsila E, Watson T, Tse HF, Lip GY. New insights on endothelial progenitor cell subpopulations and their angiogenic properties. J Am Coll Cardiol 2008;51:669-71.

10. Rosenzweig A. Circulating endothelial progenitors - cells as biomarkers. N Engl J Med 2005;353:1055-7.

11. Egan CG, Caporali F, Huqi AF, Zito MC, Focardi M, Mondillo S, et al. Reduced levels of putative endothelial progenitor and CXCR4+ cells in coronary artery disease: kinetics following percutaneous coronary intervention and association with clinical characteristics. Thromb Haemost 2009;101:1138-46.

12. Ergun S, Tilki D, Hohn HP, Gehling U, Kilic N. Potential implications of vascular wall resident endothelial progenitor cells. Thromb Haemost 2007;98:930-9.

13. Hill JM, Zalos G, Halcox JP, Schenke WH, Waclawiw MA, Quyyumi AA, et al. Circulating endothelial progenitor cells, vascular function, and cardiovascular risk. N Engl J Med 2003;348:593-600.
14. Guven H, Shepherd RM, Bach RG, Capoccia BJ, Link DC. The number of endothelial progenitor cell colonies in the blood is increased in patients with angiographically significant coronary artery disease. J Am Coll Cardiol 2006;48:1579-87.

15. Sieveking DP, Buckle A, Celermajer DS, Ng MK. Strikingly different angiogenic properties of endothelial progenitor cell subpopulations: insights from a novel human angiogenesis assay. J Am Coll Cardiol 2008;51:660-8.

16. Timmermans F, Van Hauwermeiren F, De Smedt M, Raedt R, Plasschaert F, De Buyzere ML, et al. Endothelial outgrowth cells are not derived from CD133+ cells or CD45+ hematopoietic precursors. Arterioscler Thromb Vasc Biol 2007;27:1572-9.

17. Koch AE, Harlow LA, Haines GK, Amento EP, Unemori EN, Wong WL, Pope RM, Ferrara N. Vascular endothelial growth factor. A cytokine modulating endothelial function in rheumatoid arthritis. J Immunol 1994;152:4149-56.

18. Grisar J, Aletaha D, Steiner CW, Kapral T, Steiner S, Seidinger D, et al. Depletion of endothelial progenitor cells in the peripheral blood of patients with rheumatoid arthritis. Circulation 2005;111:204-11.

19. Yiu KH, Wang S, Mok MY, Ooi GC, Khong PL, Lau CP, et al. Role of circulating endothelial progenitor cells in patients with rheumatoid arthritis with coronary calcification. J Rheumatol 2010;37:529-35.

20. Aubry MC, Maradit-Kremers H, Reinalda MS, Crowson CS, Edwards WD, Gabriel SE. Differences in atherosclerotic coronary heart disease between subjects with and without rheumatoid arthritis. J Rheumatol 2007;34:937-42.

21. Fadini GP, Coracina A, Baesso I, Agostini C, Tiengo A, Avogaro A, et al. Peripheral blood CD34+KDR+ endothelial progenitor cells are determinants of subclinical atherosclerosis in a middle-aged general population. Stroke 2006;37:2277-82.

22. Stefano R, Barsotti MC, Melillo E, Iorio M, Santoni T, Armani C, et al. The prostacyclin analogue iloprost increases circulating endothelial progenitor cells in patients with critical limb ischemia. Thromb Haemost 2008;100:871-7.

J Rheumatol 2010;37:479-81; doi:10.3899/jrheum.091341 